\title{
Learning Community in Foreign Language Learning
}

\author{
Yuhuan Zhang ${ }^{1, \text { a * }}$ \\ ${ }^{1}$ School of Foreign Languages, China West Normal University, China \\ ${ }^{1}$ No. 1 Shi Da Road, Shunqing District, Nanchong, 637009, Sichuan, China \\ ajuliezhyh@163.com
}

Keywords: Aphasia; Learning community; Foreign language education.

\begin{abstract}
Our traditional model of foreign language teaching and the reality of foreign language classroom teaching cause to Chinese people's collective aphasia in the process of cross-communication, so it is necessary for foreign language teaching to find a feasible way in order to make up for the deletions of the indigenous cultures. Members of learning community communicate and cooperate with each other in a situated environment and they need to abide by their making rules; their differences can also be respected. That compensates for misunderstandings and embarassings coming from our foreign language education. Thus, it is helpful for the virtuous development of our foreign language teaching.
\end{abstract}

\section{Introduction}

With the development of information technology and the competition of economic globalization becoming fiercer, we are entering an age of information and an age dominated by knowledge. It is possible for every Chinese person to experience or touch different cultures in their daily life, which come from foreign countries or thought styles. Nowadays, an increasing number of Chinese people begin to learning English because English is related with their different entrance examinations, their promotion, their professional qualification, their salary, their further study, etc, but not because English can be important to their jobs or their daily life. It is acknowledged that Chinese children begin to learn English even in Kindergarten. Furthermore, it cannot be denied that English teaching and learning in our country have gotten remarkable achievements; meanwhile, it must have existed some educational disadvantages and geographical weaknesses. Especially in traditional education, teachers put all the students with different diversity and characteristics in the same space and teach them the same materials. In that case, it was never envisioned to teach learners in all their diversity, discern each student's particular blend of needs and capabilities, and effectively defeat various obstacles to learning while avoiding students disruptiveness.[1] How to avoid the phenomenon appearing in learning English for Chinese students and arouse their interest of learning English is obviously important and is worthy of every English teacher's consideration in China. To some degree, information technology makes it possible to take different students' study needs into account and learning community comes into being. Learning community, to some degree, breaks through the limitation of space and time in terms of learners and brings great convenience to the learners; every learner can get profits from the learning community, such as getting more information about the same topic, brainstorming with others in the community, making up for the inadequacy of his or her own understanding, discarding the dross and selecting the essence from the members of the same community.

\section{Literature Review}

Beyond all doubt, all the studies have been researched on the basis of former ones which left abundant materials relating with learning community and for that reason more and more people can begin to focus on researches on learning community and begin to set about doing relating researches. 
Relating Definition. In order to know more about learning community, it is necessary to know about relating definitions. It is obvious that an increased focus on collaborative learning among members of the community, who work in teams, share ideas and resources and create things together. A community is often associated with a geographical locality, perhaps a town or village, where people interact with neighbors, and may be involved with local schools, societies or religious groups. But in the modern world some people interact with others online more than they do locally face-to-face. So the concept of community has been broadened to encompass the online world.[2] Community emphasizes the connections or ties among the members of the community. Moreover, the connections and ties can be created and maintained not just because of their communication, and the community has its own special characteristics: a shared purpose or purposes; shared values or beliefs; shared practices or ways of interacting[3].

Related Researches on Learning Community. In educational fields, the exploration of learning community can be traced back to the American educator_-John Dewey's concept of school. Dewey thought that school was society; education was life experience and school was a form of social life. He pointed out that schools were not really places to learn knowledge and skills, but a social organization. Therefore, accepting education is not only to prepare for the future life, but accepting education itself is an important part of social life. Although at that time he did not explicitly put forward the concept of learning community, many of his ideas are consistent with the current ideas of learning community. Japanese professor Manabu Sato described the learning community school in Japan as a living way of a wide variety of people living together. A Swedish educator, Oscar Olsson advocated a way of mass adult education, which required all the participants sitting in the circle and it got the name_-learning circle. The two notable characteristics of it are that the learning way is simple and every can participate in the activity, although he or she has different level of learning proficiency; every member of the circle is equal, has the same chance to express his or her own idea and has a voice in planning study. The core value of learning circle in Sweden happens to have the same view with learning community today. At present, not only normal institutions of higher education but also the leading research universities, and the various levels of schools in our country, even the kindergartens are doing researches in theoretical and experimental study on learning community. The theory and practice of learning community has been developed and has become the fashion that the education and the world care about and chase. What's more important, the theory and practice of learning community has spread through other fields and has made a contribution to learning-oriented organization in economic and political development. But most of the former materials emphatically emphasize the concept of learning community and construct a learning community according to the reality or the special objects in the special geographical space. Researchers seldom have done studies on learners themselves. This paper, on the basis of the reality of research background, lays emphasis on constructing learning community from learners' standpoints and it will help learners get more profits from the community.

\section{The Construction of Learning Community}

In our English classes, most of the English teachers ignore every student's personality and they usually use cramming method of teaching, which has a destructive effect on capacity for sustainable development and life-long learning ability. It is common to see such phenomena in foreign language teaching. Teaching methods cannot match the students' learning orientation, motivation and needs, so that causes to refusal and strong protest of teaching environment. ${ }^{[4]}$ On account of the real environment of foreign language teaching, constructing learning community is to accelerate and reflect foreign language teaching.

Need - the Premise of Building Learning Community. Need refers to a mental state in which organisms, lack of some deficiency, make efforts to make up for meeting a psychological situation and the reflection of living conditions and external demands. Christian Mastro divides needs into five types: physiological need, safety need, belongingness and love need(social need), respect need and 
self-actualization need.[5] Learning community, to some degrees, satisfies every member's social need and respect need because learning community can provide members with environment of mutual respect, mutual respect, democracy and equality and safety, in which every subject in the community experiences happiness of seeking truth and exploring life through mutual association and cooperation in comfortable and harmonious atmosphere.[6] All the subjects of foreign language learning community have mutual interaction and harmonious relationship in order to achieve their sharing best goal: English and Chinese cultures have equal dialogue and mutual communication, with the purpose of inheriting, carrying forward and creating Chinese culture. All subjects from community, not only teachers and students but also Chinese cultural experts, do not arrange their own positions. They respect personal difference, cooperate with each other and every member can maximize his own advantages to achieve the maximization and optimization of their sharing goals. They are experiencing the cultural crashes in reality from English and Chinese cultures; meanwhile, they suggest corresponding strategy in order to decrease misunderstanding and mystery in cross-communication. Their English-Chinese cultural study is not enslaved to anybody because their teaching aims, teaching tasks and teaching contents are not designed by teachers, but those come from the mutual communication and negotiation of all the members of the learning community. It is easy for them to develop interpersonal communication and get source information through their mutual support, help and courage.

Real Task —- the Content of Learning Community. All the contents that teachers teach are divorced from reality. What they teach is not the relationship between things but knowledge fragment [7] _ that is the image of the foreign language teaching classroom. Teachers retell the contents of English textbooks and students copy the teachers' understanding of the textbooks. The teachers design learning tasks in order to make students get English language knowledge and cultural knowledge only from the textbooks but what the students get is difficult to be transferred to students' social practice. Real task means the task that students have met in their real life before or they have not met but it is highly possible to happen in real scenario. In learning community, presetting a real task — a communication on Chinese traditional Spring Festival between a Chinese and a English native person, such a task is crucial for Chinese people and they can speak some relevance to festival. In that case, it can evoke members to explore and experience their mutual understanding of Spring Festival. Every subject tries to look for English expression of Chinese cultural tradition on Chinese customs, eating habits and dress around the task and the theme of Spring Festival. The culture carding and comprehension of the subjects in the learning community is not entirely equivalent and their proficiency is not the same. Through their ways of communication, it is helpful to complement, promote and improve each other's understanding of knowledge and culture. Perhaps subjects of the community have some barriers of using English to express and propagate Chinese traditional culture, but they can get deep comprehension and understanding of English and Chinese cultures through mutual communication and clearing up confusions. Transferring such real tasks to our real life environment, it is easy for students to rise to the occasions and the embarrassment of collective silence will no more happen.

Equal Dialogue — - the Method of Learning Community. Equal dialogue is the basic method of effecting learning community; the process of equal dialogue is also the process of operating learning community. Dialogue is the embodiment of communication and exchanging ideas among member of the community. Subjects of the community use language as a medium of communication, knowledge, thought and affections on the basis of mutual respect and mutual equality in comfortable and harmonious atmosphere. Dialogue teaching is a model of instruction which brings about knowledge and teaching significance in free, equal, respecting and trusting environments among members in the community. Members from different places, races and family backgrounds, have different understandings even on the same Chinese traditional cultural phenomenon. They can share their different experiences and ideas, judge others' acquaintances, but their judgments are neither right nor wrong and there is no reference answer. What they try to do is helpful for the members to cooperate, communicate with each other and experience the environments existing in reality. 


\section{Summary}

Due to the educational reality- - traditional English classes educate English talents, who have many words about target language culture but experience collective silence about Chinese culture output, this paper gives a new angle of constructing English learning community, which is a challenge for traditional English teaching and makes English educators be lost in thought. The construction of learning community means more people and the one get together to think about the same problem, which helps individual to work out further and get new knowledge. Because of members' mutual communication and cooperation, they improve the efficiency of the whole community and contribute to master and promotion of members' learning capacity. But the theories relating with learning community are complex, so it is necessary to enrich our foreign language theory and compose the new chapter of our foreign language teaching from the standpoint of cognitive theory, constructivism learning theory and scene and sensation theory.

\section{References}

[1] Darling-Hammond, L. (1997). The right to learn: A blueprint for creating schools that work. San Francisco:Jossey-Bass. Quoted in Clifford

[2] H. Edwards. (2011). Educational Change: From Traditional Education to Learning Communities. Rowman\& Littlefield Education: Plymouth.

[3] Clifford H. Edwards. (2011). Educational Change: From Traditional Education to Learning Communities. Rowman\& Littlefield Education: Plymouth.

[4] Karen Kear. (2011). Online and social networking communities: a best practice guide for educators. Routledge: New York.

[5] Wang Yan. (2003). General Psychology. People's Education Press: Beijing

[6] Zheng Wei.( 2007). Learning Community__An Ideal Structure in the Environment of Cultural Ecology. Science and Education Press: Beijing.

[7] Priscilla Norton\&Karin M. Wiburg. Wu Hongjian\& Ni Nanqi translation. 2002. Information Technology and Teaching Innovation. China Light Industry Press: Beijing. 